Research

\title{
Association of thyroid function with arterial pressure in normotensive and hypertensive euthyroid individuals: $A$ cross-sectional study
}

\author{
Katerina Saltiki1,2, Paraskevi Voidonikola ${ }^{3}$, Kimon Stamatelopoulos ${ }^{3}$, \\ Emily Mantzou ${ }^{1}$, Christos Papamichael ${ }^{3}$ and Maria Alevizaki*1,2
} \begin{abstract}
Alexandra Hospital, Athens University School of Medicine, Athens, Greece
Email: Katerina Saltiki - saze@otenet.gr; Paraskevi Voidonikola - evinavoid@yahoo.com;

Kimon Stamatelopoulos - stamatelopoulosk@yahoo.gr; Emily Mantzou - endocrineunit@yahoo.gr;

Christos Papamichael - papchris1@yahoo.com; Maria Alevizaki* - mani@otenet.gr

* Corresponding author
\end{abstract}

Address: ${ }^{1}$ Endocrine Unit, Evgenidion Hospital, Athens University School of Medicine, Athens, Greece, ${ }^{2}$ Endocrine Unit, Dept Medical Therapeutics, Alexandra Hospital, Athens University School of Medicine, Athens, Greece and 3Vascular Laboratory, Dept of Medical Therapeutics,

Published: 29 September 2008

Thyroid Research 2008, 1:3 doi:10.1 186/1756-6614-1-3
Received: 24 June 2008

Accepted: 29 September 2008

This article is available from: http://www.thyroidresearchjournal.com/content/I/I/3

(c) 2008 Saltiki et al; licensee BioMed Central Ltd.

This is an Open Access article distributed under the terms of the Creative Commons Attribution License (http://creativecommons.org/licenses/by/2.0), which permits unrestricted use, distribution, and reproduction in any medium, provided the original work is properly cited.

\begin{abstract}
Background: Overt hypothyroidism has been associated with arterial hypertension and increased arterial stiffness. Results in euthyroid individuals have been conflicting. We investigated associations of thyroid function with systolic (SAP) and diastolic (DAP) arterial pressure in euthyroid subjects.

Methods: 3 II euthyroid individuals ( 185 women, mean age $43.9 \pm 9$ ) without a history of diabetes attending a preventive medicine program were examined. Subjects receiving thyroxine $(10.6 \%)$ were excluded; $19.3 \%$ had hypertension, $43 \%$ had a family history for hypertension. TSH, fT4, thyroid autoantibodies, insulin, glucose were measured. The "fT4.TSH product", which has been suggested as a T4 resistance-index, was calculated.
\end{abstract}

Results: TSH range was $0.1-8$, median $1.4 \mathrm{mU} / \mathrm{L}$, fT4 range was $1 \mathrm{I} .5-25.2 \mathrm{pmol} / \mathrm{L}$, median 17.4 . TSH and the "fT4.TSH product" were positively associated with DAP $(p<0.03$, for both associations). In the subgroup of individuals with TSH levels $0.36-2.5 \mathrm{mU} / \mathrm{L}$, both TSH and the "fT4.TSH product" were positively correlated with SAP $(r=+0.133 p=0.044, r=+0.152 p=0.026)$ and $\operatorname{DAP}(r=+0.243 p<0.001, r=+0.252 p<0.001$ respectively); in multivariate analysis the "fT4.TSH product" was a significant predictor of DAP independently of HOMA-IR and BMI ( $<$ $0.00 I$ ). Similar associations were found when only the non-hypertensive subjects were analysed ( $P$ $=0.004)$. Hypertensive patients had higher TSH levels $(p=0.02)$ and belonged more frequently to the subgroup with $\mathrm{TSH}>2 \mathrm{mU} / \mathrm{L}(35.3 \%$ vs $21.3 \%, \mathrm{p}=0.045)$.

Conclusion: In euthyroid individuals the association of thyroid function with diastolic arterial pressure remains significant even when a stricter "normal range" for TSH levels is considered. The "free T4.TSH" product appears to be an even stronger predictor of DAP, independently of HOMA insulin resistance index and obesity. 


\section{Background}

Thyroid hormones influence cardiovascular function [1,2] and modulate the vascular response [3]. Overt hypothyroidism may be associated with hypertension and various adverse cardiovascular effects [4-9].

Subclinical hypothyroidism has also been associated with arterial hypertension, mostly diastolic [10-12], as well as with atherosclerosis $[13,14]$ and coronary heart disease $[15,16]$ in both sexes. However these findings have not been consistent. In overt and especially in subclinical hypothyroidism normotensive patients are quite frequently observed particularly in younger age groups [1720]. Thus the risk of mild thyroid failure for cardiovascular disease and, subsequently, the need for a therapeutic intervention in this group, remain controversial $[1,19,21]$.

It is interesting that such associations have also been reported for euthyroid individuals. TSH variation within the normal range has been associated with alterations in various cardiovascular parameters including arterial pressure $[11,22,23]$ and lipid profile $[11,24]$. Early markers of atherosclerosis such as increased intima media thickness [25] and impaired endothelial function [26-28] may be detected among patients with borderline thyroid function. It has further been reported that hypertensive patients may have a tendency for impaired thyroid function [29]; however these results have not always been confirmed [20].

The mechanism through which slightly impaired thyroid function might influence arterial blood pressure is not clear; increased systemic vascular resistance, premature atherosclerosis and increased arterial stiffness may all be involved $[2,30]$. It has been argued that in the hypothyroid state, the sympathetic and the renin-angiotensinaldosterone systems are possibly implicated in the homeostasis of arterial pressure [31,32]. Thyroxine replacement therapy may reverse the cardiovascular effects and may result in the regulation of arterial pressure in subjects with subclinical hypothyroidism [8,32-35]. However, it has been suggested that the mechanisms involved in these associations may not be attributed to impaired thyroid hormone action; genetic factors alone may influence the regulation of both arterial blood pressure and circulating TSH levels as well as the individually determined set point of thyroid function [28].

The purpose of our study was to investigate associations of thyroid function parameters with systolic (SAP) and diastolic (DAP) arterial pressure in clinically euthyroid subjects.

\section{Methods}

We studied 311 euthyroid individuals (185 women, 126 men, mean age $43.9 \pm 9$ ) who visited the cardiovascular laboratory in response to an announcement for free examination for unrecognized features of the metabolic syndrome in the outpatients' clinic of our hospital over a period of 12 months. Thyroid function tests were included in the protocol.

Exclusion criteria were a history of diabetes mellitus (previously diagnosed according to the American Diabetes Association criteria), overt coronary heart disease or a previous history of stroke. The presence of hypertension was defined as systolic and/or diastolic blood pressure higher than $139 \mathrm{mmHg}$ and/or $89 \mathrm{mmHg}$, respectively and/or current use of antihypertensive drugs.

Patients receiving thyroxine as well as those who were on drugs possibly affecting thyroid function such as lithium, amiodarone or $\gamma$-interferon were excluded from the analysis $(10.6 \%)$. Of the studied individuals included in the analysis (165 women, 113 men) 19.3\% had hypertension and $43 \%$ had a family history for hypertension. The study was approved by the institutional Ethics Committee and all subjects gave their informed consent.

Using a standard mercury sphygmomanometer and after 5 minutes of rest, three consecutive measurements of arterial pressure were obtained while all subjects were in a sitting position and the mean was calculated. Height and weight were also measured with subjects wearing indoor clothes without shoes. Body mass index (BMI) was calculated according to the formula weight $(\mathrm{kg}) /$ height $\left(\mathrm{m}^{2}\right)$. Waist and hip perimeter $(\mathrm{cm})$ measurements were performed and waist to hip ratio (W/H R) was used to evaluate fat distribution. Current drug therapy and clinical history were also recorded. Ninety one (55.1\%) of the women participating in the study were premenopausal.

Fasting blood samples were obtained by venipuncture between 08:00-09:00 h. Serum TSH and free thyroxine were measured using chemiluminescent immunometric assays with the DPC Immulite 200 (Siemens). Serum antithyroid antibodies (antiTPO, antiTG) analysis was performed by RIA using the reagents Brahms DINOtest (Brahms diagnostica $\mathrm{GmbH}$, Berlin). Reference range was: TSH 0.36-4 mU/L, fT4 9-25 pmol/L, antiTPO < $60 \mathrm{IU} / \mathrm{ml}$, antiTG $<60 \mathrm{IU} / \mathrm{ml}$. Data were also analysed using a TSH cutoff of either 2 or $2.5 \mathrm{mU} / \mathrm{L}$. Glucose levels (measured immediately using an automated analyser Integra 400, Roche) and insulin levels (in specimens kept frozen at $20^{\circ} \mathrm{C}$ until analysis was performed by IRMA, Biosource Europe SA, Nivelles, Belgium) were also estimated. Basal insulin resistance index (Homeostasis Model Assessment, HOMA) was calculated according to the formula: Insulin 
resistance $=\mathrm{FI} \times \mathrm{G} / 22.5$, where $\mathrm{FI}=$ fasting insulin $(\mu \mathrm{U} /$ $\mathrm{ml})$ and $\mathrm{G}=$ fasting glucose $(\mathrm{mmol} / \mathrm{L})$.

The "fT4.TSH product", derived by multiplying TSH by fT4, was calculated. Previous studies have suggested that this index, referred to as T4 resistance-index, may determine the fT4-TSH set-point for each person. TSH appears to contribute by $85 \%$ to the fT4.TSH variance $[28,36]$.

\section{Statistical analysis}

Statistical analysis was done using the SPSS statistical package. All descriptive data are presented as mean \pm SD. Linear regression analysis was used to investigate correlations between continuous variables. In the multivariate analysis we included as possible confounders all the variables for which there was some correlation which was statistically significant or which showed a tendency to be significant in the univariate analysis. Student's $t$ - test was used to compare mean values between groups where the distribution was normal. Chi - square test with Yates' continuity correction was used, or chi - square for linear association as appropriate.

\section{Results}

TSH range was $0.1-8$, median $1.4 \mathrm{mU} / \mathrm{L}$; fT4 range was 11.5-25.2, median $17.4 \mathrm{pmol} / \mathrm{L}$. The clinical and biochemical characteristics of the population are shown in table 1 .

TSH and the "fT4.TSH product" were positively associated with diastolic arterial pressure (DAP) $(\mathrm{r}=+0.134, \mathrm{p}=$ 0.029 and $r=+0.156, p=0.014$ respectively). In the subgroup of individuals with TSH levels $0.36-2.5 \mathrm{mU} / \mathrm{L}(\mathrm{n}=$ 238), TSH levels were positively correlated with systolic ( $\mathrm{r}$ $=+0.133, \mathrm{p}=0.04)$ and diastolic arterial pressure $(\mathrm{r}=$ $+0.243, \mathrm{p}<0.001$, figure 1 ). Similarly, in the same subgroup, the "fT4.TSH product" was positively correlated with SAP $(\mathrm{r}=+0.152, \mathrm{p}=0.026)$ and DAP $(\mathrm{r}=+0.252$, $\mathrm{p}$

Table I: Baseline characteristics of the studied population

\begin{tabular}{lccc}
\hline & $\%$ & Mean \pm SD & Range \\
\hline Sex (men) & 40.5 & & \\
Age (years) & & $43.9 \pm 9$ & $34.9-52.9$ \\
BMI & & $26.9 \pm 4.7$ & $19.0-43.3$ \\
Waist-to-hip Ratio & & $0.87 \pm 0.12$ & $0.52-1.39$ \\
Hypertension & 19.3 & & \\
Dyslipidemia & 41 & & \\
Family history of hypertension & 43 & & \\
Smoking & 42 & & \\
TSH (mU/L) & & $1.6 \pm 1.01$ & $0.1-8.0$ \\
TT4 (pmol/L) & & $17.8 \pm 2.2$ & $11.5-25.2$ \\
TT4.TSH product & & $26.4 \pm 15.8$ & $1.04-92$ \\
Systolic blood pressure (mmHg) & & $119.7 \pm 20.3$ & $85-195$ \\
Diastolic blood pressure (mmHg) & & $77.2 \pm 12.3$ & $55-120$ \\
HOMA-IR index & & $1.88 \pm 1.4$ & $0.4-11.0$ \\
\end{tabular}

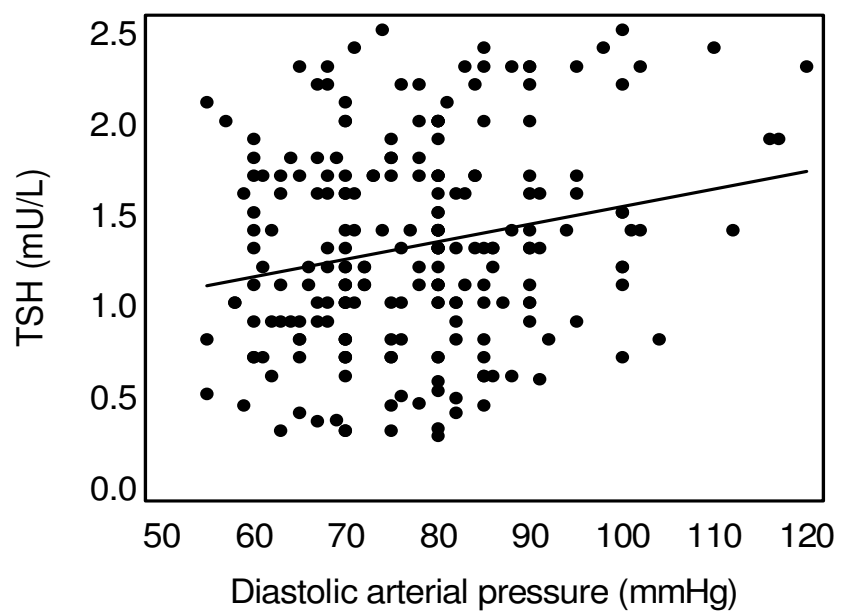

Figure I

Association of diastolic arterial blood pressure with TSH levels in the subgroup of apparently healthy subjects with TSH levels in the narrow "normal range" (0.36-2.5 $\mathrm{mU} / \mathrm{L})(r=+0.243, \mathrm{p}<0.00 \mathrm{I})$.

$<0.001$, figure 2) respectively. A multivariate analysis (step model) was performed considering associations of DAP with age, sex, cardiovascular risk factors such as HOMA-IR and BMI and thyroid function parameters. In this model, the "fT4.TSH product" was a significant independent predictor of DAP (table 2). The association of DAP with TSH was no longer significant when age, BMI and HOMA-IR were taken into account. Similarly, when only the normotensive subjects with TSH levels $0.36-2.5$

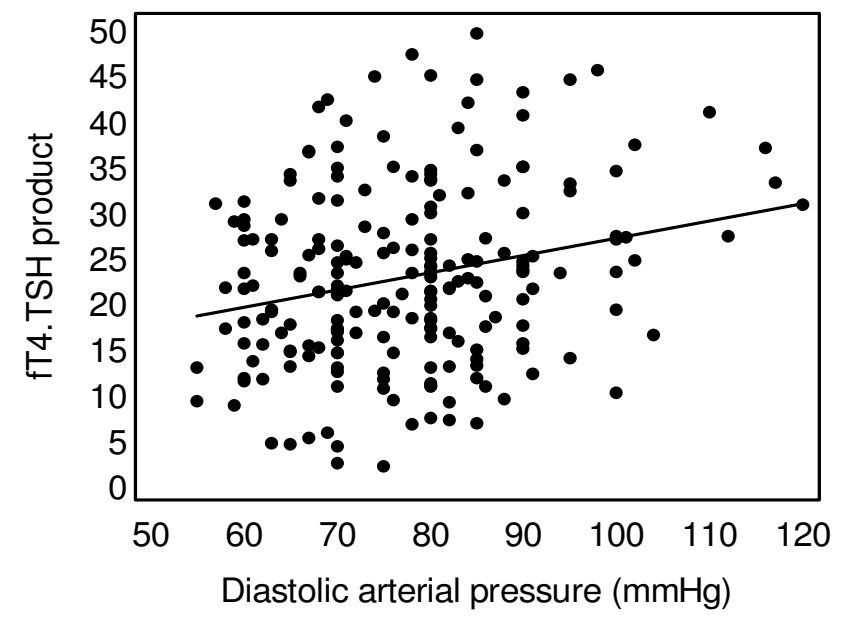

Figure 2

Association of diastolic arterial blood pressure with the "fT4.TSH product" in the subgroup of apparently healthy subjects with TSH in the narrow "normal range" $(0.36-2.5 \mathrm{mU} / L)(r=+0.252, \mathrm{p}<0.00 \mathrm{I})$. 
Table 2: Stepwise multiple regression model for predicting diastolic arterial pressure in apparently healthy individuals with TSH $0.36-$ $2.5 \mathrm{mU} / \mathrm{L}$

\begin{tabular}{cccccc}
\hline Variable & Predictor & Beta & T & Significance $P$ & Overall R $(\%)$ \\
\hline Diastolic arterial pressure & Age & 0.193 & 3.103 & 0.002 & 0.295 \\
& Sex & -0.222 & -3.625 & $<0.001$ & 0.007 \\
& HOMA-IR & 0.203 & 2.705 & 0.032 & 0.001 \\
\hline
\end{tabular}

$\mathrm{mU} / \mathrm{L}$ were analysed $(\mathrm{n}=203)$, TSH levels and the "fT4.TSH product" showed positive association with DAP $(\mathrm{r}=+0.208, \mathrm{p}=0.004$ and $\mathrm{r}=+0.212, \mathrm{p}=0.004$ respectively, Pearson's correlation).

Hypertensive patients had higher TSH levels $(1.92 \pm 1.04$ vs $1.54 \pm 1.3, \mathrm{p}=0.02$, t-test) and belonged more frequently to the subgroup with TSH $>2 \mathrm{mU} / \mathrm{L}$ compared to normotensive ones (35.3\% vs $21.3 \%, \mathrm{p}=0.045 \mathrm{x}^{2}$-test). Normotensive subjects with a family history for hypertension belonged more frequently to the subgroup with TSH $>2 \mathrm{mU} / \mathrm{L}$ although this finding was not significant $(\mathrm{p}=$ 0.056, Pearson chi-square).

There were no significant differences in the occurrence of hypertension in the patients with positive thyroid autoantibodies (either antiTG or antiTPO).

In the subgroup with subclinical hyperthyroidism $(n=17$, $5.7 \%$ ) there were no associations between TSH levels and systolic and/or diastolic blood pressure.

\section{Discussion}

Our study has demonstrated that in euthyroid individuals with TSH levels in the narrow "normal range" (0.36-2.5 $\mathrm{mU} / \mathrm{L})$, diastolic as well as systolic arterial blood pressure is positively associated with TSH levels. These associations remained significant even when only normotensive subjects were considered. Similar positive associations have also been reported by other investigators [11,12]. Asvold et al [22] in a large population study which included more than 30000 euthyroid subjects, found a positive linear association between systolic and diastolic arterial pressure and TSH levels. Furthermore, the fifth Tromso study showed that systolic and diastolic blood pressure were higher in euthyroid individuals belonging to the highest versus the lowest serum TSH quartile of the normal range [23]. On the other hand, in another recent communitybased study mean DAP and SAP did not differ between individuals with subclinical hypothyroidism and euthyroid subjects [20]. Similarly, no such associations were reported in other studies concerning either younger [34,37] or older [14,17] individuals; however in these studies there were significant associations of mild thyroid failure with other cardiovascular parameters such as left ventricular diastolic dysfunction [34] or atherosclerosis and coronary heart disease [14,37].

We have further demonstrated that the "fT4.TSH product" is also positively associated with diastolic as well as with systolic blood pressure. This association was independent of age, sex, insulin resistance and obesity. The same result was found even when only normotensive subjects were considered for the analysis. This marker has been rarely used in the literature and may reflect an individually determined fT4-TSH relationship $[28,36]$; it may not represent thyroid function but it may be indicative of an altered sensitivity of peripheral tissues to thyroid hormones. This means that higher TSH levels for a standard value of freeT4 are associated with higher arterial blood pressure and thus probably with impaired peripheral vascular function [28]. There are no reports in the literature for similar associations concerning arterial pressure. Although the significance of this product cannot be clearly defined, it is interesting that recently vascular indices have again been associated with this marker. Fernandez-Real et al reported significant associations of the same marker with insulin sensitivity and endothelial function in euthyroid individuals [28]. In this study, patients with reduced endothelium-dependent vasodilatation had "fT4.TSH product" values above the median and also increased TSH levels. Based on these results a hypothesis of possible genetic variations which could influence vascular function and serum TSH as well as the individually determined thyroid set point, might be supported [28,38].

Another finding in our study concerns the subjects with a history of hypertension. Higher TSH levels were associated with a history of hypertension. Moreover, hypertensive subjects belonged more frequently to the subgroup with $\mathrm{TSH}>2 \mathrm{mU} / \mathrm{L}$. As we have previously shown, TSH values above these levels, may be associated with endothelial dysfunction [26] and increased arterial stiffness [30] compared to euthyroid subjects with TSH levels lower than $2 \mathrm{mU} / \mathrm{L}$. Similar results have been reported in the population study of Asvold et al [22]. They showed that when subjects with TSH levels in the upper part of the normal range (3-3.5 $\mathrm{mU} / \mathrm{L})$ were compared to those with 
TSH levels in the lower part of the normal range (0.5-0.99 $\mathrm{mU} / \mathrm{L}$ ), the odds ratio for hypertension in the former group was 1.98 for men and 1.23 for women, respectively. In another study, by Iqbal et al, TSH levels were higher among individuals with diastolic hypertension [23]. Finally, Gumieniac et al showed that euthyroid hypertensive subjects had slightly impaired thyroid function with lower fT4 index and higher TSH levels compared to normotensive subjects [29]. On the other hand Walsh et al reported no differences in the prevalence of hypertension in subjects with subclinical hypothyroidism compared to euthyroid ones, after adjustment for age and sex [20]. In another large study concerning an older population, no differences were observed in the prevalence of hypertension, cardiovascular outcomes and mortality between the overt hypothyroidism, subclinical hypothyroidism and normal thyroid function groups [19]. In agreement with other studies we did not find any associations between thyroid autoantibody positivity and the presence of hypertension [20].

Finally, normotensive individuals with a family history of hypertension belonged more frequently to the subgroup with TSH $>2 \mathrm{mU} / \mathrm{L}$ although this association just missed statistical significance. A similar finding has been reported by Gumieniac et al in a study of hypertensive families [38]. In this study normotensive euthyroid subjects with a family history of hypertension had higher TSH levels compared to those with a negative history. In the same study, a familial aggregation of high-normal TSH levels was observed; these investigators speculated that there may be common genetic variants which affect both the pituitarythyroid axis set point and the regulation of arterial pressure. As it has been mentioned previously, "the fT4.TSH product" could be a phenotypic marker of each individual's set point of thyroid function, probably genetically determined. Thus, one might suggest that our results indirectly concur with the observations reported by Fernandez-Real et al [28] and by Gumieniac et al [38]. Studies in spontaneously hypertensive rats have confirmed that arterial pressure regulation is in part mediated by TRH [39]; similarly, polymorphic variants of genes such as the TSH receptor gene or the type 2 iodothyronine deiodinase genes could be implicated in both insulin resistance and the regulation of arterial pressure and TSH levels $[40,41]$.

We did not find associations between arterial pressure and TSH at the lower levels of the normal range or with the presence of subclinical hyperthyroidism. This could be due to the small sample of subjects with subclinical hyperthyroidism. In the literature there are reports for such associations $[20,22]$ although these results are not consistent [42].
A limitation of our results was the relatively small number of studied individuals. However, several of our findings point to the same direction.

\section{Conclusion}

In conclusion, in euthyroid individuals the associations of thyroid function with arterial blood pressure remain significant even when a stricter "normal range" for TSH levels is considered. The "freeT4.TSH" product appears to be an even stronger predictor of diastolic arterial blood pressure, independently of HOMA insulin resistance index and obesity.

\section{Abbreviations}

BMI: Body Mass Index; DAP: Diastolic Arterial Pressure; fT4: free Thyroxine; HOMA-IR: Homeostasis Model Assessment-Insulin Resistance Index; SAP: Systolic Arterial Pressure; T3: Triiodothyronine; T4: Thyroxine; TSH: Thyroid Stimulating Hormone; W/H R: Waist-to-Hip Ratio.

\section{Competing interests}

The authors declare that they have no competing interests.

\section{Authors' contributions}

KS drafted the manuscript and performed the statistical analysis. PV participated in the design of the study and collected the data. KS performed the statistical analysis. EM carried out the immunoassays. CP conceived the study. MA performed the statistical analysis, conceived the study and participated in its design and coordination. All authors read and approved the final manuscript.

\section{References}

I. Biondi B, Cooper DS: The clinical significance of subclinical thyroid dysfunction. Endocr $\operatorname{Rev} 2008,29: 76-131$.

2. Klein I, Ojamaa K: Thyroid hormone and the cardiovascular system. N Engl J Med 200I, 344:501-509.

3. Danzi S, Klein I: Thyroid hormone and blood pressure regulation. Curr Hypertens Rep 2003, 5:5 I3-520.

4. Endo T, Komiya I, Tsukui T, Yamada T, Izumiyama T, Nagata H, Kono $\mathrm{S}$, Kamata K: Re-evaluation of a possible high incidence of hypertension in hypothyroid patients. Am Heart $J 1979$, 98:684-688.

5. Saito I, Ito K, Saruta T: Hypothyroidism as a cause of hypertension. Hypertension 1983, 5: I I2-II 5.

6. Kotsis V, Alevizaki M, Stabouli S, Pitiriga V, Rizos Z, Sion M, Zakopoulos N: Hypertension and hypothyroidism: results from an ambulatory blood pressure monitoring study. J Hypertens 2007, 25:993-999.

7. Botella-Carretero Jl, Gomez-Bueno M, Barrios V, Caballero C, Garcia-Robles R, Sancho J, Escobar-Morreale HF: Chronic thyrotropin-suppressive therapy with levothyroxine and short-term overt hypothyroidism after thyroxine withdrawal are associated with undesirable cardiovascular effects in patients with differentiated thyroid carcinoma. Endocr Relat Cancer 2004, I I:345-356.

8. Streeten DH, Anderson GH Jr, Howland T, Chiang R, Smulyan H: Effects of thyroid function on blood pressure. Recognition of hypothyroid hypertension. Hypertension 1988, I I:78-83.

9. Saito I, Saruta T: Hypertension in thyroid disorders. Endocrinol Metab Clin North Am 1994, 23:379-386. 
10. Luboshitzky R, Herer P: Cardiovascular risk factors in middleaged women with subclinical hypothyroidism. Neuro Endocrinol Lett 2004, 25:262-266.

II. Luboshitzky R, Aviv A, Herer P, Lavie L: Risk factors for cardiovascular disease in women with subclinical hypothyroidism. Thyroid 2002, 1 2:421-425.

12. Nagasaki T, Inaba M, Kumeda Y, Hiura Y, Shirakawa K, Yamada S, Henmi $Y$, Ishimura E, Nishizawa $Y$ : Increased pulse wave velocity in subclinical hypothyroidism. J Clin Endocrinol Metab 2006, 91:154-158.

13. Cappola AR, Ladenson PW: Hypothyroidism and atherosclerosis. J Clin Endocrinol Metab 2003, 88:2438-2444.

14. Hak AE, Pols HA, Visser TJ, Drexhage HA, Hofman A, Witteman JC: Subclinical hypothyroidism is an independent risk factor for atherosclerosis and myocardial infarction in elderly women: the Rotterdam Study. Ann Intern Med 2000, I 32:270-278.

15. Walsh JP, Bremner AP, Bulsara MK, O'Leary P, Leedman PJ, Feddema $P$, Michelangeli V: Subclinical thyroid dysfunction as a risk factor for cardiovascular disease. Arch Intern Med 2005, I 65:2467-2472.

16. Asvold BO, Bjoro T, Nilsen TI, Gunnell D, Vatten LJ: Thyrotropin levels and risk of fatal coronary heart disease: the HUNT study. Arch Intern Med 2008, I 68:855-860.

17. Takashima N, Niwa Y, Mannami T, Tomoike H, Iwai N: Characterization of subclinical thyroid dysfunction from cardiovascular and metabolic viewpoints: the Suita study. Circ J 2007, 7I:19I-195

18. Bergus GR, Mold JW, Barton ED, Randall CS: The lack of association between hypertension and hypothyroidism in a primary care setting. J Hum Hypertens 1999, I 3:231-235.

19. Cappola AR, Fried LP, Arnold AM, Danese MD, Kuller LH, Burke GL, Tracy RP, Ladenson PW: Thyroid status, cardiovascular risk, and mortality in older adults. JAMA 2006, 295: I033-I04I

20. Walsh JP, Bremner AP, Bulsara MK, O'Leary P, Leedman PJ, Feddema $P$, Michelangeli $V$ : Subclinical thyroid dysfunction and blood pressure: a community-based study. Clin Endocrinol (Oxf) 2006, 65:486-491.

21. Surks MI, Ortiz E, Daniels GH, Sawin CT, Col NF, Cobin RH, Franklyn JA, Hershman JM, Burman KD, Denke MA, et al.: Subclinical thyroid disease: scientific review and guidelines for diagnosis and management. JAMA 2004, 291:228-238.

22. Asvold BO, Bjoro T, Nilsen TI, Vatten LJ: Association between blood pressure and serum thyroid-stimulating hormone concentration within the reference range: a population-based study. I Clin Endocrinol Metab 2007, 92:84 I-845.

23. Iqbal $A$, Figenschau $Y$, Jorde $R$ : Blood pressure in relation to serum thyrotropin: The Tromso study. J Hum Hypertens 2006, 20:932-936.

24. Asvold BO, Vatten LJ, Nilsen TI, Bjoro T: The association between TSH within the reference range and serum lipid concentrations in a population-based study. The HUNT Study. Eur J Endocrinol 2007, I 56:181-186.

25. Dullaart RP, de Vries R, Roozendaal C, Kobold AC, Sluiter W]: Carotid artery intima media thickness is inversely related to serum free thyroxine in euthyroid subjects. Clin Endocrinol (Oxf) 2007, 67:668-673.

26. Dagre AG, Lekakis JP, Protogerou AD, Douridas GN, Papaioannou TG, Tryfonopoulos DJ, Papamichael CM, Alevizaki M: Abnorma endothelial function in female patients with hypothyroidism and borderline thyroid function. Int J Cardiol 2007, I I 4:332-338.

27. Lekakis J, Papamichael C, Alevizaki M, Piperingos G, Marafelia P, Mantzos J, Stamatelopoulos S, Koutras DA: Flow-mediated, endothelium-dependent vasodilation is impaired in subjects with hypothyroidism, borderline hypothyroidism, and high-normal serum thyrotropin (TSH) values. Thyroid |997, 7:4| |-4|4.

28. Fernandez-Real JM, Lopez-Bermejo A, Castro A, Casamitjana R, Ricart W: Thyroid function is intrinsically linked to insulin sensitivity and endothelium-dependent vasodilation in healthy euthyroid subjects. I Clin Endocrinol Metab 2006, 9 1:3337-3343.

29. Gumieniak O, Perlstein TS, Hopkins PN, Brown NJ, Murphey LJ, Jeunemaitre $X$, Hollenberg NK, Williams GH: Thyroid function and blood pressure homeostasis in euthyroid subjects. J Clin Endocrinol Metab 2004, 89:3455-346I.

30. Dagre AG, Lekakis JP, Papaioannou TG, Papamichael CM, Koutras $\mathrm{DA}$, Stamatelopoulos SF, Alevizaki M: Arterial stiffness is increased in subjects with hypothyroidism. Int J Cardiol 2005, 103:1-6.

31. Fommei E, lervasi G: The role of thyroid hormone in blood pressure homeostasis: evidence from short-term hypothyroidism in humans. J Clin Endocrinol Metab 2002, 87:1996-2000.

32. Fletcher AK, Weetman AP: Hypertension and hypothyroidism. J Hum Hypertens 1998, I 2:79-82.

33. Dernellis J, Panaretou M: Effects of thyroid replacement therapy on arterial blood pressure in patients with hypertension and hypothyroidism. Am Heart J 2002, I43:718-724.

34. Biondi B, Fazio S, Palmieri EA, Carella C, Panza N, Cittadini A, Bone F, Lombardi G, Sacca L: Left ventricular diastolic dysfunction in patients with subclinical hypothyroidism. J Clin Endocrinol Metab 1999, 84:2064-2067.

35. Turhan S, Tulunay C, Ozduman Cin M, Gursoy A, Kilickap M, Dincer I, Candemir B, Gullu S, Erol C: Effects of thyroxine therapy on right ventricular systolic and diastolic function in patients with subclinical hypothyroidism: a study by pulsed wave tissue Doppler imaging. J Clin Endocrinol Metab 2006, 9 I:3490-3493.

36. Yagi H, Pohlenz J, Hayashi Y, Sakurai A, Refetoff S: Resistance to thyroid hormone caused by two mutant thyroid hormone receptors beta, $R 243 Q$ and $R 243 W$, with marked impairment of function that cannot be explained by altered in vitro 3,5,3'-triiodothyroinine binding affinity. J Clin Endocrinol Metab 1997, 82:1608-1614.

37. Kvetny J, Heldgaard PE, Bladbjerg EM, Gram J: Subclinical hypothyroidism is associated with a low-grade inflammation, increased triglyceride levels and predicts cardiovascular disease in males below 50 years. Clin Endocrinol (Oxf) 2004, 6 I:232-238

38. Gumieniak O, Hurwitz S, Perlstein TS, Ngumezi UC, Hopkins PN, Jeunemaitre $X$, Williams GH: Aggregation of high-normal thyroid-stimulating hormone in hypertensive families. J Clin Endocrinol Metab 2005, 90:5985-5990.

39. Garcia SI, Alvarez AL, Porto PI, Garfunkel VM, Finkielman S, Pirola C]: Antisense inhibition of thyrotropin-releasing hormone reduces arterial blood pressure in spontaneously hypertensive rats. Hypertension 200I, 37:365-370.

40. Fiorito M, Torrente I, De Cosmo S, Guida V, Colosimo A, Prudente S, Flex E, Menghini R, Miccoli R, Penno G, et al.: Interaction of DIO2 T92A and PPARgamma2 PI2A polymorphisms in the modulation of metabolic syndrome. Obesity (Silver Spring) 2007, I 5:2889-2895.

4I. Peeters RP, Deure WM van der, Beld AW van den, van Toor H, Lamberts SW, Janssen JA, Uitterlinden AG, Visser TJ: The Asp727Glu polymorphism in the TSH receptor is associated with insulin resistance in healthy elderly men. Clin Endocrinol (Oxf) 2007, 66:808-815

42. Volzke H, Alte D, Dorr M, Wallaschofski H, John U, Felix SB, Rettig $\mathrm{R}$ : The association between subclinical hyperthyroidism and blood pressure in a population-based study. J Hypertens 2006, 24:1947-1953.

Publish with Bio Med Central and every scientist can read your work free of charge

"BioMed Central will be the most significant development for disseminating the results of biomedical research in our lifetime. "

Sir Paul Nurse, Cancer Research UK

Your research papers will be:

- available free of charge to the entire biomedical community

- peer reviewed and published immediately upon acceptance

- cited in PubMed and archived on PubMed Central

- yours - you keep the copyright 